\title{
Staging of esophageal carcinoma
}

\author{
Jeffrey A. Hagen, MD
}

Tom R. DeMeester, MD

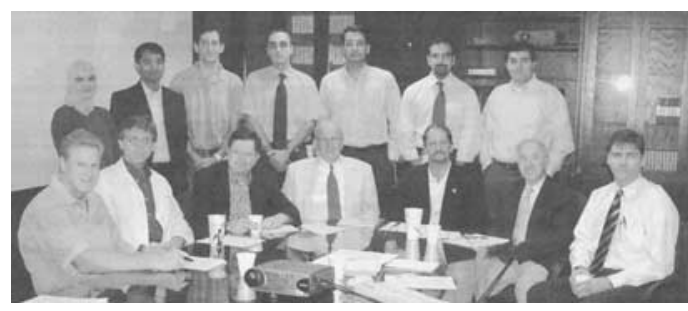

USC Thoracic and Foregut Research

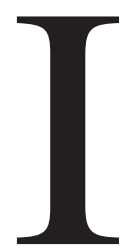

n this month's issue of the Journal, Rice and colleagues ${ }^{1}$ report a thorough retrospective analysis of prospectively collected data titled "Role of Clinically Determined Depth of Tumor Invasion in the Treatment of Esophageal Carcinoma" The report has 3 major conclusions. First, the authors conclude that clinical staging with endoscopic ultrasonography (EUS) reliably reflects pathologic staging with an accuracy of $87 \%$. This observation adds to the growing body of data indicating that EUS is the most reliable method available for the clinical staging of esophageal cancer. Second, they conclude that the tumor and nodal responses to induction therapy (chemoradiotherapy) are linked. This implies that a benefit seen in downstaging $\mathrm{T}$ (tumor) indicates a similar downstaging of $\mathrm{N}$ (nodal disease). They then ask the following pertinent question: Does downstaging $\mathrm{T}$ portend an improved survival? The answer is partially provided in their third conclusion that when nodal disease persists, the downstaging of the tumor does not improve survival. This implies that even though $\mathrm{T}$ and $\mathrm{N}$ stage are linked in both their occurrence and response to induction therapy, $\mathrm{N}$ is predominant and independent of $\mathrm{T}$ in predicting survival. With these points made, they attempt to identify, with clinical staging methodology, subgroups of patients who are likely to benefit from induction therapy. Overall, the report is a movement away from the current trend toward the belief that neoadjuvant therapy is the standard of care for all patients with esophageal cancer. Their movement is justified by the failure of prospective randomized clinical trials to show a convincing and consistent benefit of neoadjuvant therapy in carcinoma of the esophagus (Table 1). ${ }^{2-8}$

In an effort to identify subgroups of patients who would benefit from induction therapy, Rice and colleagues ${ }^{1}$ have made 3 major observations. First, they observed that patients with clinical stage T3 N0 disease appear to have a benefit from induction therapy (see Rice and colleagues' Figure 2). Several concerns about their data need to be addressed before incorporating these observations into clinical practice. First, they have clearly shown that there is often a difference between the clinical assessment of tumor depth (clinical T stage) and the depth of tumor invasion on the histologic examination of the resected specimen (pathologic $\mathrm{T}$ stage). When this occurs, they have chosen to explain the difference as a result of the downstaging of the tumor by means of induction therapy when it is equally plausible that it might be due to, at least in some cases, inaccurate initial clinical staging; that is, patients with lesser disease might have had their disease overstaged, resulting in a perceived but not true downstaging of the tumor by means of induction therapy. Rice and colleagues' Appendix Table 1 shows the overall accuracy of EUS in patients treated with surgical intervention alone. For T3 tumors, staging errors occurred in 18 of 112 patients, with $15(13 \%)$ having been overstaged. In most cases the overstaged tumors were actually T1 in depth. Applying this information to the group of 28 patients depicted in Rice and colleagues' Figure 2, one could expect that 4 patients with apparent T3 N0 disease actually had T1 to T2 N0 disease with a potential for better survival. This could explain the difference in survival shown in patients with clinical stage T3 N0 disease because the difference between the expected (untreated patients) and observed (treated patients) survival at 5 years was only 4 patients. The second concern is that expected survival of the clinically staged T3 N0 subgroup on 
TABLE 1. Randomized trials of neoadjuvant chemoradiotherapy followed by surgical intervention versus surgical intervention alone for esophageal cancer

\begin{tabular}{|c|c|c|c|c|c|c|c|c|c|c|}
\hline & \multirow[b]{2}{*}{ Date } & \multirow{2}{*}{$\begin{array}{l}\text { Cell } \\
\text { type }\end{array}$} & \multirow[b]{2}{*}{$\mathbf{n}$} & \multicolumn{2}{|c|}{ CRT + S arm } & \multirow{2}{*}{$\begin{array}{c}\text { S alone } \\
\text { arm }\end{array}$} & \multirow[b]{2}{*}{ p-CR } & \multicolumn{2}{|c|}{ Survival (median) } & \multirow{2}{*}{$\begin{array}{c}P \\
\text { value }\end{array}$} \\
\hline & & & & Chemotherapy & Radiotherapy & & & CRT + S & $S$ alone & \\
\hline Nygaard ${ }^{2}$ & 1992 & $\mathrm{Sq}$ & 47 & $C, B$ & $35 \mathrm{~Gy}$ & 41 & NA & (<12mo) & $(<12 \mathrm{mo})$ & .3 \\
\hline & & & & 2 cycles & Nonconc & TTE & & 3-y: 17\% & $3-y: 9 \%$ & $\mathrm{~N} / \mathrm{A}$ \\
\hline Apinop 3 & 1994 & $\mathrm{Sq}$ & 35 & C, 5-FU & $40 \mathrm{~Gy}$ & 34 & $26 \%$ & (9.7 mo) & (7.4 mo) & .4 \\
\hline & & & & 2 cycles & Conc & TTE & & 3-y: 26\% & $3-y: 20 \%$ & $\mathrm{~N} / \mathrm{A}$ \\
\hline Le Prise ${ }^{4}$ & 1994 & $\mathrm{Sq}$ & 41 & $\mathrm{C}, 5-\mathrm{FU}$ & $20 \mathrm{~Gy}$ & 45 & $10 \%$ & $(12 \mathrm{mo})$ & (12 mo) & .56 \\
\hline & & & & 2 cycles & Nonconc & & & 3-y: 19\% & 3-y: 14\% & N/A \\
\hline Walsh $^{5}$ & 1996 & A & 58 & C, 5-FU & $40 \mathrm{~Gy}$ & 55 & $25 \%$ & (16 mo) & $(11 \mathrm{mo})$ & $.01 *$ \\
\hline Bosset $^{6}$ & 1997 & $\mathrm{Sq}$ & 143 & $\begin{array}{l}2 \text { cycles } \\
\text { C } \\
2 \text { cycles }\end{array}$ & $\begin{array}{l}\text { Conc } \\
37 \mathrm{~Gy} \\
\text { Nonconc }\end{array}$ & $\begin{array}{l}\text { mixed } \\
139 \\
\text { TTE }\end{array}$ & $26 \%$ & $\begin{array}{l}3-y: 32 \% \\
\text { (18.6 mo) }\end{array}$ & $\begin{array}{l}3-y: 6 \% \\
(18.6 \mathrm{mo})\end{array}$ & $\begin{array}{l}.01 \\
.78\end{array}$ \\
\hline Urba $^{7}$ & 2001 & $\begin{array}{l}\text { A } 75 \% \\
\text { Sq } 25 \%\end{array}$ & 50 & $\begin{array}{l}\text { C, V, } 5 \text {-FU } \\
2 \text { cycles }\end{array}$ & $\begin{array}{l}45 \mathrm{~Gy} \\
\text { Conc }\end{array}$ & $\begin{array}{l}50 \\
\text { THE }\end{array}$ & $28 \%$ & $\begin{array}{l}(16.9 \mathrm{mo}) \\
3-\mathrm{y}: 30 \%\end{array}$ & $\begin{array}{l}(17.6 \mathrm{mo}) \\
3-y: 16 \%\end{array}$ & $\begin{array}{l}\mathrm{N} / \mathrm{A} \\
.15\end{array}$ \\
\hline MRC Trial8 & 2002 & $\begin{array}{l}\text { Sq } 31 \% \\
\text { A } 66 \%\end{array}$ & 400 & $\begin{array}{l}\text { C, } 5 \text {-FU } \\
2 \text { cycles }\end{array}$ & Optional & 402 & $4 \%$ & $\begin{array}{l}(16.8 \mathrm{mo}) \\
2-y: 43 \%\end{array}$ & $\begin{array}{l}(13.3 \mathrm{mo}) \\
2-y: 34 \%\end{array}$ & .004 \\
\hline
\end{tabular}

$C R T+S$, Chemoradiotherapy followed by surgical intervention; $S$, surgical intervention; $p-C R$, pathologic complete response; $X R T, x$-ray therapy; $S q$, squamous; $C$, cisplatin; $B$, bleomycin; $T T E$, transthoracic echocardiography; $N S$, not significant; 5 - $F U, 5$-fluorouracil; $A$, adenocarcinoma; $V$, vinblastine; nonconc, nonconcurrent; conc, concurrent; $N / A$, not available.

* See text for concerns about statistical methodology and the potential for stage bias between groups.

the basis of their rather convoluted statistical method is not as good as the actuarial survival reported in other clinical series. We and others have reported a $40 \%$ to $85 \%$ 5-year survival in pathologic T3 N0 disease treated by means of surgical intervention alone. ${ }^{9-11}$ These results are clearly at odds with their current expected T3 N0 survival of $15 \%$ at 5 years, with a median survival of 18 months estimated by means of multivariable analysis (Rice and colleagues' Figure 2). In fact, their expected survival is worse than the actuarial survival they reported for T3 N0 disease of $26 \%$ with a median survival of 26 months in the Journal in 1996. ${ }^{12}$ Furthermore, their expected survival calculated for T3 N0 disease (Rice and colleagues' Figure 2) is worse than that calculated for $\mathrm{N} 1$ disease with any $\mathrm{T}$ stage (Rice and colleagues' Figure 4). Most centers report a lower survival with $\mathrm{N} 1$ disease..$^{9-11}$ On the basis of our review of their data, we fear that the model they used to estimate the expected survival of the group undergoing surgical intervention alone might not reflect clinical experience. Why their predictive equation gives such a disparity is unclear. The third concern is the criteria used to define patients for inclusion in the clinical T3 N0 subgroup. It is possible that the benefit of induction therapy that they have shown for clinical T3 N0 disease would have been negated by inclusion of all patients with this stage of disease who received induction therapy and not just those who completed therapy and went on to surgical intervention. The usual approach in reporting multimodality therapy results is to use the intention-to-treat model. If this was done, it is possible that the number of patients who did not undergo surgical intervention because of death, toxicity, or progression of disease while receiving induction therapy would outweigh any potential benefit achieved with the combined therapy. The mortality rate reported for induction therapy alone is as high as $7 \%$ to $10 \%,{ }^{13-15}$ with toxicity or progression of disease preventing the planned surgical intervention in another $4 \%$ to $20 \%$. $^{7,16,17}$

The second major observation made by Rice and colleagues ${ }^{1}$ is that patients who received induction therapy for clinical N1 disease but who were found to have pathologic N0 disease at resection had a survival, on the basis of their multivariable model, that was better than that expected for patients undergoing surgical intervention alone. The significance level of this comparison was borderline $(P=.07)$ and suggests that if there is a benefit to downstaging $\mathrm{N}$, the magnitude is small. The issue of clinical downstaging and the errors induced by overstaging described above with T3 disease apply equally to patients with $\mathrm{N} 1$ disease. The report by Rice and colleagues published in the Journal in 199918 showed an accuracy of $80 \%$ for EUS assessment of N1 disease. This would suggest that as many as 3 of the 14 patients receiving induction therapy for clinical N1 disease in the current series might have been overstaged. That is, they might have had N0 disease in the first place, with a potential for better survival. Once again, inaccurate staging could explain the difference in survival shown in Rice and colleagues' Figure 4 because the variance between the expected and observed survival at 5 years was only 2 patients.

The third major observation made by Rice and colleagues ${ }^{1}$ is that induction therapy might actually harm patients with clinical T1 and T2 disease when node metastases are absent on clinical staging. This finding, we believe, is 
their most important and valuable contribution. In this situation clinical understaging (deeper invasion than EUS suggests) might explain some of the difference between the observed (treated patients) and expected (untreated patients) survivals (Rice and colleagues' Figure 3). Rice and colleagues' Appendix Table 1 shows that of the 63 patients with clinical T1 or T2 disease, 10 (16\%) had their disease overstaged. Applying this estimate to the 11 patients analyzed in Rice and colleagues' Figure 3, one would expect 2 patients to have had their disease understaged, with a potential for poorer survival than expected for clinical T1 or T2 tumors. Elimination of these patients with understaged disease from the analysis would certainly improve the observed survival, perhaps to as high as $30 \%$ at 5 years, but still well below the expected survival predicted by the authors' multivariable model. Therefore, it seems reasonable to conclude that induction therapy could be potentially detrimental and should not be offered to patients with $\mathrm{T} 1$ or T2 N0 disease.

A reasonable question to ask is why survival should be compromised after induction therapy for early esophageal cancer. The answer to this question is not clear, nor has an explanation been offered in the article. Inferences drawn from prospective studies on induction therapy followed by surgical intervention might provide an explanation. ${ }^{7,19,20}$ It has been widely accepted that although induction therapy does not improve overall survival compared with surgical intervention alone, the subgroup of patients who have a complete pathologic response to induction therapy have a better survival than those who respond less, respond not at all, or have only surgical intervention. What is overlooked is that patients who respond less or not at all to induction therapy have a corresponding lower survival than the average survival for the induction therapy group as a whole and the group undergoing surgical intervention only. It is conceivable that the diminished survival is due to a delay in surgical therapy of patients whose tumors are resistant to the induction therapy. Delays that average more than 3 months have been reported. ${ }^{21}$ Induction therapy might also be detrimental to the host immune system, increasing the opportunity for systemic progression. Consequently, in patients with early disease, when complete surgical resection results in a high likelihood of cure, induction therapy might result in a poorer outcome than would have occurred with initial surgical resection. In other words, the negative consequences of delaying effective therapy or suppressing host immune function by means of routine administration of induction therapy might only be worthwhile in the small subgroup of patients whose tumors are sensitive to the induction therapy and who would not have been cured with surgical intervention alone.

The authors have taken the first step to begin to identify subgroups of patients who might benefit from induction therapy, and for this they are to be congratulated. They propose selection on the basis of EUS staging and recommend induction therapy for those with clinical T3 N0 and any N1 disease. The inherent error rate in EUS staging, however, poses problems with this approach. Furthermore, data exist to suggest that the very patients they propose are likely to derive a benefit from induction therapy are the same patients who are least likely to manifest such a response. Law and associates ${ }^{22}$ have shown, in a prospective trial of neoadjuvant therapy for squamous cell cancer, that the clinical tumor stage was more advanced in nonresponders than in responders, with a higher percentage of $\mathrm{T} 3$ tumors in the nonresponding group. Jiao and coworkers ${ }^{23}$ made a similar observation in a study with minimally invasive staging. They showed that a response to induction therapy was more likely to occur in the absence of node metastases than when lymph node metastases were present. In the latter situation, fewer than $15 \%$ responded. Consequently, we are left with a dilemma. Most patients with advanced disease do not respond to induction therapy but need it. Patients with early disease are more likely to respond to induction therapy but need it less and, according to the report of Rice and colleagues, ${ }^{1}$ might be harmed.

We agree with the authors that the only solution is the selective application of induction therapy. However, how can we identify the responders? Rice and colleagues ${ }^{1}$ advocate clinical staging with EUS. We have our doubts. Ideally, molecular biologic characterization of the tumors will provide the answers.

\section{References}

1. Rice TW, Blackstone EH, Adelstein DJ, et al. Role of clinically determined depth of tumor invasion in the treatment of esophageal carcinoma. J Thorac Cardiovasc Surg. 2003;125:1091-102.

2. Nygaard K, Hagen S, Hansen HS, et al. Preoperative radiotherapy prolongs survival in operable esophageal cancer: a randomized, multicenter study of preoperative radiotherapy and chemotherapy. The second Scandinavian trial in esophageal cancer. World J Surg. 1992; 16:1104-10.

3. Apinop C, Puttisak P, Preecha. A prospective study of combined therapy in esophageal cancer. Hepatogastroenterology. 1994;41:391-3.

4. Le Prise E, Etienne Pl, Meunier B, et al. A randomized study of chemotherapy, radiation therapy, and surgery versus surgery for localized squamous cell carcinoma of the esophagus. Cancer. 1994;73: $1779-84$.

5. Walsh TN, Noonan N, Hollywood D, Kelly A, Keeling N, Hennessy TP. A comparison of multimodal therapy and surgery for esophageal adenocarcinoma. N Engl J Med. 1996;335:462-7.

6. Bosset JF, Gignoux M, Triboulet JP, et al. Chemoradiotherapy followed by surgery compared with surgery alone in squamous-cell cancer of the esophagus. N Engl J Med. 1997;337:161-7.

7. Urba SG, Orringer MB, Turrisi A, Iannettoni M, Forastiere A, Strawderman M. Randomized trial of preoperative chemoradiation versus surgery alone in patients with locoregional esophageal carcinoma [see comments]. J Clin Oncol. 2001;19:305-13.

8. Medical Research Council Oesophageal Cancer Working Group. Surgical resection with or without preoperative chemotherapy in oesophageal cancer: a randomized controlled trial. Lancet. 1002;359:172733. 
9. Nigro JJ, DeMeester SR, Hagen JA, et al. Node status in transmural esophageal adenocarcinoma and outcome after en bloc esophagectomy. J Thorac Cardiovasc Surg. 1999;117:960-8.

10. Steup WH, De Leyn P, Deneffe G, Van Raemdonck D, Coosemans W, Lerut T. Tumors of the esophagogastric junction. Long-term survival in relation to the pattern of lymph node metastasis and a critical analysis of the accuracy or inaccuracy of pTNM classification. $J$ Thorac Cardiovasc Surg. 1996;111:85-5.

11. Altorki NK, Skinner DB. Should en bloc esophagectomy be the standard of care for esophageal carcinoma. Ann Surg. 2001;234:581-9.

12. Killinger WA Jr, Rice TW, Adelstein DJ, et al. Stage II esophageal carcinoma: the significance of T and N. J Thorac Cardiovasc Surg. 1996;111:935-40.

13. Lew JI, Gooding WE, Ribeiro U Jr, Safatle-Ribeiro AV, Posner MC. Long-term survival following induction chemoradiotherapy and esophagectomy for esophageal carcinoma. Arch Surg. 2001;136:73743.

14. Urba SG, Orringer MB, Perez-Tamayo C, Bromberg J, Forastiere A. Concurrent preoperative chemotherapy and radiation therapy in localized esophageal adenocarcinoma. Cancer. 1992;69:285-91.

15. Liedman B, Johnsson E, Merke C, Ruth M, Lundell L. Preoperative adjuvant radiochemotherapy may increase the risk in patients undergoing thoracoabdominal esophageal resections. Dig Surg. 2001;18: 169-75.

16. Heath EI, Burtness BA, Heitmiller RF, et al. Phase II evaluation of preoperative chemoradiation and postoperative adjuvant chemotherapy for squamous cell and adenocarcinoma of the esophagus. J Clin Oncol. 2000;18:868-76.
17. Keller SM, Ryan LM, Coia LR, et al. High dose chemoradiotherapy followed by esophagectomy for adenocarcinoma of the esophagus and gastroesophageal junction: results of a phase II study of the Eastern Cooperative Oncology Group. Cancer. 1998;83:1908-16.

18. Rice TW, Blackstone EH, Adelstein DJ, et al. N1 esophageal carcinoma: the importance of staging and downstaging. J Thorac Cardiovasc Surg. 2001;121:454-64.

19. Ancona E, Ruol A, Santi S, et al. Only pathologic complete response to neoadjuvant chemotherapy improves significantly the long term survival of patients with resectable esophageal squamous cell carcinoma: final report of a randomized, controlled trial of preoperative chemotherapy versus surgery alone. Cancer. 2001;91: 2165-74.

20. Roth JA, Pass HI, Flanagan MM, et al. Randomized clinical trial of preoperative and postoperative chemotherapy with cisplatinum, vindesine, and bleomycin for carcinoma of the esophagus. $J$ Thorac Cardiovasc Surg. 1988;96:242-8.

21. Kelsen DP, Ginsberg R, Pajak TF, et al. Chemotherapy followed by surgery compared with surgery alone for localized esophageal cancer. N Engl J Med. 1998;339:1979-84.

22. Law S, Fok M, Chow S, Chu KM, Wong J. Preoperative chemotherapy versus surgical therapy alone for squamous cell carcinoma of the esophagus: a prospective randomized trial [see comments]. J Thorac Cardiovasc Surg. 1997;114:210-7.

23. Jiao X, Krasna MJ, Sonett J, et al. Pretreatment surgical lymph node staging predicts results of trimodality therapy in esophageal cancer. Eur J Cardiothorac Surg. 2001;19:880-6.

\section{JTCVS On-Line Manuscript Submission and Review}

\section{Please visit http://www.editorialmanager.com/jtcvs/}

Effective September 15, 2001, authors and reviewers may submit manuscripts and reviews electronically via Editorial Manager, our new Web-based system with full electronic submission, review, and status update capabilities.

As we move from paper to electronic submissions, the Editorial Office will make proxy submissions of all manuscripts accompanied by a diskette containing the electronic files of the text, tables, and figures. Editors, authors, and reviewers will receive automatic e-mails when significant events occur.

We strongly encourage all authors and reviewers to use Editorial Manager. Although we will continue to accommodate the submission of paper manuscripts for some months, our goal is to be completely electronic within 9 to 12 months.

All individuals currently in our database for whom we have e-mail addresses will receive via e-mail a system-assigned username and password that can be used to log in to the system without prior registration. All those not receiving the e-mail must register the first time they use the system.

As with any broad systemic change, the conversion to the new system will take some time to complete. We ask your patience as we replace our in-office database with the new system. We also encourage you to take advantage of the speed and efficiency that the new system will provide for us all: editor, author, reviewer, and publisher. 